\title{
Man with enormous trilobar goiter
}

\author{
L. M. Sena ${ }^{1} \cdot$ M. Barale ${ }^{2}$
}

Received: 7 March 2015 / Accepted: 9 March 2015 / Published online: 2 April 2015

(C) Italian Society of Endocrinology (SIE) 2015

The 188 tiles which decorate the paneled ceiling of the Sala Magna in Muratori Cravetta's Palace, one of the noble residences in Savigliano (Cuneo, Italy), reflect medieval style and habits.

Among noble families' coats of arms, animals and scenes of everyday life dated about 1474-1477, we can recognize the painting of a man with enormous trilobar goiter (Fig. 1), attributed to Giovanni Antonio Molineri's working group (1577-1631), a late mannerist painter born in Savigliano.

The subject has coarse facial features with thick lips and broad nose which are suggestive of cretinism. Maybe he was a servant of nobility, as often these people have been employed [1]. Alternatively, he might have been painted with the purpose of creating astonishment and fear, feelings that, associated with the mystery that surrounded the origins of the goiter, had always excited the people's imagination.

The high prevalence of goiter and cretinism in the surroundings of Cuneo and in the whole Piedmont could explain the frequent representation of these characters in the figurative art of this area.

\section{Conflict of interest No Conflict of Interest.}

Ethical approval This article does not contain any studies with human participants or animals performed by any of the authors.

Informed Consent No Informed Consent.

M. Barale

marco.barale@unito.it

1 Division of Clinical Pathology, Department of Laboratory Medicine, University of Turin, 10126 Turin, Italy

2 Division of Endocrinology, Diabetology and Metabolism, Department of Medical Sciences, University of Turin, 10126 Turin, Italy

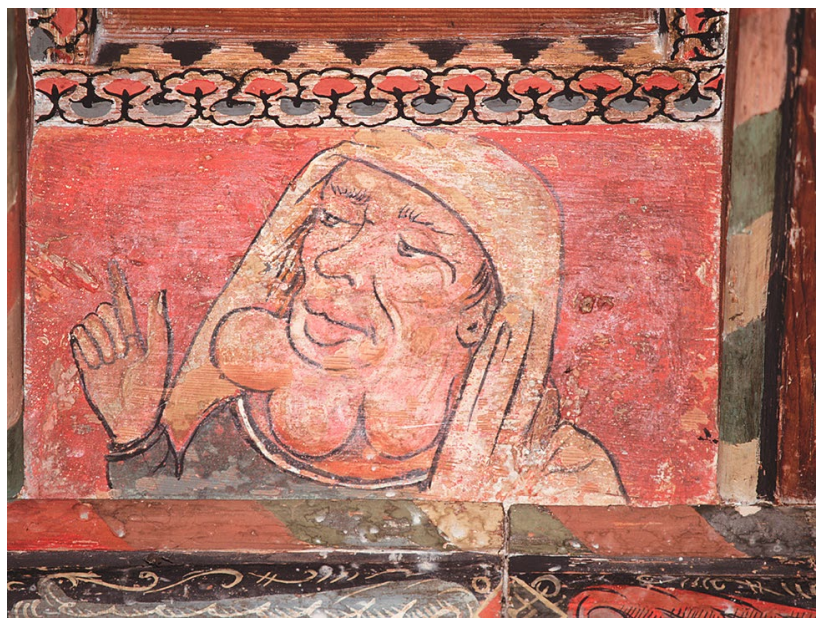

Fig. 1 Tile representing a man with an enormous trilobar goiter

\section{Reference}

1. Guaraldi F (2012) Court dwarfs: an overview of European paintings from fifteenth to eighteenth century. Endocrine 42(3):736-738 